\title{
ИННОВАЦИИ В РАЗВИТИИ БАНКОВСКОГО СЕКТОРА
}

\author{
(C) 2019 Букина Виктория Анатольевна \\ магистрант \\ Самарский государственный экономический университет, Россия, Самара \\ E-mail: bukinav_17@mail.ru \\ (c) 2019 Коновалова Мария Евгеньевна \\ доктор экономических наук, профессор \\ Самарский государственный экономический университет, Россия, Самара
}

В статье рассмотрен процесс развития банковского сектора, поднята и проанализирована проблема оценки финансового состояния заемщика в процессе кредитования. Проведен анализ инноваций и инновационного процесса в экономической науке, даны определения этих терминов.

Ключевые слова: инновации, инновационные технологии, инновационный процесс, банковский сектор, рынок банковских услуг, оценка кредитоспособности, риски.

Развитие рынка банковских услуг является закономерным процессом, затрагивающим интересы многих субъектов хозяйственных взаимоотношений, причем не только банков, как непосредственных производителей, а, прежде всего, предприятий и организаций реального сектора экономики, как потребителей банковских услуг.

Происходит смещение акцентов от продажи массовых банковских продуктов и услуг к разработке и реализации индивидуальных, ориентированных на конкретного корпоративного потребителя услуг. Подобного рода проблем у банковских учреждений в период функционирования монобанковской системы не возникало, поэтому должного внимания им не уделялось в отечественной теории и практике. В этой связи возникает необходимость исследований теоретических и практических аспектов развития финансового сектора экономики, степени участия в этом процессе не только государства, но и отечественных коммерческих банков.

Экономическая устойчивость является главным компонентом общей устойчивости предприятия, так как она является характерным индикатором стабильного превышения доходов над расходами. Категория «экономическая устойчивость компании» являет собой емкий и многогранный социально - экономический феномен, который как общественно - значимое явление возникает вместе с определенным уровнем развития рыночных отношений.

Для успешного функционирования коммерческих банков крайне сложно переоценить роль оценки кредитоспособности клиента до подписания договора о кредитовании, определения лимита возможного отчисления денежных средств в резерв, так как многие компании оказывающие услуги являются необходимыми при поддержке развития предприятий в стране и их закрытие несет за собой ряд не только экономических, но и социальных проблем.

Степень развития банковского сектора как одного из основных элементов финансовой системы характеризуется эффективностью проводимой денежно-кредитной политики в значительной мере, определяющей реальные возможности российской экономики для осуществления структурных преобразований, способных обеспечить устойчивое развитие страны, уменьшить зависимость экономики от конъюнктуры на мировых сырьевых рынках и в целом способствовать повышению ее конкурентоспособности.

Инструменты цифровой экономики, проводя автоматизированный анализ неструктурированных данных при помощи алгоритмов на базе искусственного интеллекта с возможностью машинного обучения, с применением биометрии, позволяют сформировать гибкое, надежное технологическое пространство взаимодействия как с потребителями услуг, так и регуляторами рынка, благодаря усовершенствованной системе отчетности. В таких условиях организациям необходимо успевать за новыми трендами и модернизировать эффективность своей работы. Коммерческие банки, активно ведущие инновационную наукоемкую деятельность, обеспе- 
чивают себе устойчивое положение на рынке за счет непрерывного совершенствования линейки выпускаемых продуктов и услуг.

Многие мировые страны всерьез озаботились современными тенденциями в экономике и проявляют активный интерес к цифровым технологиям. По состоянию на 2016 год, согласно данным ОЭСР, в странах-участницах организации ведутся разработки или планируются к внедрению соответствующие стратегии перевода своих экономик на цифру. В США к этому моменту был сформирован Совет консультантов по цифровой экономике при Министерстве торговли, перед которым поставлены цели по развитию интернет технологий, выработке соответствующих мер безопасности финансовых данных и поддержке научных инноваций частного сектора. В 2017 году к списку заинтересованных стран присоединилась Австралия, начав составление своей программы трансформации национальной экономики в этом направлении.

Согласно концепции российского ученого С.Ю. Глазьева существует шесть технологических укладов, каждый из которых представляет собой конгломерат технологически сопряженных эволюционно соответствующих друг другу по техническому уровню производств, в своей совокупности образующих полную линию выпуска набора качественно однородных потребительских благ. Согласно формулировке самого автора этого термина: «технологические уклады - это группы технологических совокупностей, выделяемые в технологической структуре экономики, связанные друг с другом однотипными технологическими цепями и образующие воспроизводящиеся целостности. Каждый такой уклад представляет собой целостное и устойчивое образование, в рамках которого осуществляется полный макропроизводственный цикл, включающий добычу и получение первичных ресурсов, все стадии их переработки и выпуск набора конечных продуктов, удовлетворяющих соответствующему типу общественного потребления.» [12] Обладая периодами своего зарождения (началом развития технологии), становление (широкого распространения, доминирование технологии) и устаревания (затухания развития, отмирание), один уклад сменял другой в историческом процессе экономического и промышленного развития человечества. При этом зарождение следующего уклада приходилось на фазу становления предыдущего.
Каждый технологический уклад характеризовался ключевой технологией, которая определяла вектор развития общества.

Согласно представлениям С.Ю. Глазьева, современный мир на данном этапе развития находится в преддверии шестого экономического уклада, ключевыми факторами которого будут являться интеллектуализация процессов производства и общества в целом. Интеллектуальное общество должно прийти на смену обществу потребления. Основные векторы развития - экологичность среды обитания, безотходность технологий. Повышение требований к процессам приведет к дальнейшему развитию телекоммуникаций, способов обработки информации, что даст новый виток глобализации экономики и качественному скачку в науке и промышленности. И наблюдая за тенденциями в сфере деятельности крупных компаний на мировом рынке, нельзя не согласиться, что имеют место значительные сдвиги в этом направлении. В сфере экономики происходит ее все большая интеграция с компьютерными технологиями. Этот процесс получил названия «цифровизация» или «диджитализация» (от английского слова digital - цифровой). Термин «цифровая экономика» впервые появился в 1995 году, его автор американский ученый Н. Негропонте. В целом, цифровая экономика не обладает в научной среде однозначным определением, а скорее является собирательным выражением, которое подразумевает данную сферу деятельности человека как систему экономических и социокультурных отношений, основанную на использовании цифровых технологий генерации, обработки, хранения и передачи данных [13]. Новейшие программно-аппаратные комплексы по сбору, обработке и систематизации данных позволяют строить сколь угодно детализированные модели процессов, потребительских ожиданий, повышая тем самым эффективность бизнеса и его конкурентноспособность на рынке. Применение современных информационных подходов в экономике позволяют перейти обществу от индустриальной стадии развития, где определяющими факторами производства служило производство, материальные, трудовые ресурсы и капитал, к постиндустриальной стадии. Ее доминирующие факторы - это знания и интеллектуальный капитал. Идея, воплощенная на рынке в успешный конкурентноспособный продукт, положенная в основе креативного бизнеса, ста- 
новится основным драйвером производства

Важность инноваций в постиндустриальном обществе неоспорима и требует осознанного научного подхода для ведения данного рода деятельности. Необходимо обладать компетенциями для определения типа и вида инновации и проведения мероприятий по внедрению новой идеи в производство.

Инновация как объект исследуется экономической наукой достаточно давно. Впервые термин «инновация» упомянул в своей работе «Теория экономического развития» американский ученый австрийского происхождения Йозеф Шумпетер. Он определил, что инновация - это новая комбинация производственных факторов, которая частично основывается на уже существующих достижениях, является продуктом интеллектуальной деятельности предпринимателя. При этом в понимании автора понятие предпринимателя не приравнивается ни к изобретателю новой идеи, ни к управленцу, ни к владельцу капитала. Эти субъекты исполняют важные роли в процессе создания новой комбинации, однако особая роль уделяется предпринимательскому духу, особому роду мышления, новатору чье видение экономических взаимоотношений позволяет ему вносить изменения в рыночную структуру, выводя новый продукт или услугу.

С точки зрения Й. Шумпетера, которую можно считать классической, инновации бывают следующих видов:

1. инновация как новый продукт, совершенно новый для данного типа рынка;

2. новая технология производства уже существующего товара или услуги;

3. создание нового рынка;

4. открытие или изобретение нового фактора производства;

5. построение организационной структуры в составе хозяйствующего субъекта.

Й.Шумпетер отметил также, что построение нового порой влечет за собой разрушение существующего отжившего себя порядка вещей. Так, например, внедрение станков свело на нет ремесленный ручной труд или вытеснение автомобилестроительной отраслью коннозаводческих производств ученый называет созидательным разрушением, которое необходимо для экономического развития.

С другой стороны, автор книги «Управление научно-техническими нововведениями» Брайан Твисс определяет инновацию как процесс, в котором изобретение или идея приобретает эко- номический смысл. Он заключается в получении новизны и длится от зарождения идеи до ее коммерческой реализации, охватывая комплекс отношений, производство, обмен, потребление.

В своей работе «Инновационный менеджмент» российский ученый Р.А. Фатхутдинов дает свое определение инновации - конечный результат внедрения новшества с целью изменения объекта управления и получения экономического, социального, экологического, научно-технического или другого вида эффекта. Автор разделяет понятия инновации и новшества. Под новшеством понимается конечный результат научно-исследовательской деятельности и опытно-конструкторских разработок, иными словами - уже действующий экспериментальный образец, но еще не внедренный в серийное производство и не выпущенный на рынок. Еще одним отличием видения Р.А. Фатхутдинова является вынесение за рамки инновации как таковой этапов исследования, разработки, внедрения на производство и распространения.

На основании вышеизложенного можно заключить, что инновация - это внедренный в процесс, коммерчески успешный результат творческого, инвестиционного, научно-технического процесса, способствующий значительному повышению эффективности в той или иной сфере человеческой деятельности, при этом обладающий новизной и отсутствием широкого распространения в данном сегменте рынка. Если устоявшийся технологический уклад формирует и обеспечивает механизм реализации экономических законов рыночной экономики, то инновация - это выход за рамки действующих экономических законов стоимости и ценности. Если устоявшийся технологический уклад определяет содержание рыночной стоимостной ценности и соответствие ей индивидуальной стоимостной ценности, то инновационный процесс отделяет и обособляет индивидуальную стоимость от рыночной в сторону её снижения, а индивидуальную ценность от рыночной в сторону её увеличения. В результате отдельные фирмы получают от инновации дополнительный доход(прибыль) от снижения издержек и увеличения качества предоставляемой продукции. Таким образом, инновация в рыночной экономике - это выход отдельного предприятия за пределы существующего рыночного технологического уклада, что предполагает снижение индивидуальной стоимости продукции и рост индивидуальной её ценности и в конечном 
итоге у данного предприятия образуется социально-экономический эффект.

Определение целей и задач инновации позволяет приступить к проведению исследований, необходимых для внедрения. Научные исследования являются первым этапом в процессе инновационной деятельности. Они подразделяются на фундаментальные и прикладные. Фундаментальные исследования (ФИ) необходимы для пополнения научного знания о законах, процессах, происходящих в обществе, природе и их взаимодействии между собой. Они необходимы для понимания формы и содержания исследуемого вопроса в чистом виде. Для адаптации базовых знаний под конкретную практическую задачу проводят прикладные исследования (ПИ). Они должны показать состоятельность выбранной в рамках ФИ теоретической концепции. На выходе ПИ исследователь формирует техническую документацию, методики, схемы и чертежи.

Положительное заключение по результатам исследований дает основание для разработки опытного образца. Этот этап инновационной деятельности носит название «опытно-конструкторские работы». Данный процесс подразумевает создание и последующую проверку опытных образцов новшества - продукта, технологии, процесса.

По мере завершения экспериментальной эксплуатации происходит сбор аналитической информации об испытаниях продукты и выносится решение о запуске новшества в процесс производства: вывод на рынок и диффузия инновации.

Каждый этап инновационного процесса требует тщательной подготовки и наличия ресурсов на осуществление работ. Поскольку внедрение новшества является рисковым предприятием, на каждом этапе целесообразна оценка деятельности и принятие взвешенного решения о продолжении процесса. В качестве источников финансирования, как правило, выступают собственные средства компании, а также возможно привлечение заемных средств. Наиболее затратными для инвестирования этапами выступают опытные разработки и вывод в производственный процесс. Принятие положительного решения о запуске пилотного проекта подразумевает не только настройку и запуск необходимого программного обеспечения, но и подбор и обучение необходимого персонала, способного воспринимать инновационные про- цессы, перестраиваться и соответствовать необходимым нормам. Современный финансовый сектор крайне подвержен воздействию инновационных процессов и то, на сколько эффективно будет построен процесс осуществления банковской деятельности зависит от того, на сколько быстро смогут банки и финансовые организации перестроиться и запустить инновационные процессы в кредитовании.

Следует отметить, что существующие методики определения кредитоспособности основываются на анализе бухгалтерского баланса заемщика, однако совокупность данных расчетов не всегда отражает действительную ситуацию финансового положения. Решить эту проблему в иностранных государствах помогает широкая сеть независимых аудиторских фирм, чье объективное заключение о финансовом состоянии потенциальных заемщиков облегчает работу банков. В нашей же стране аудиторское дело находится на стадии становления.

Помимо привлечения независимых аудиторских фирм, банки применяют свои собственные методики оценки финансового состояния заемщика, а также оценки рисков, которые могут повлиять на способность заемщика погашать свои кредитные обязательства перед банком.

Таким образом из вышесказанного следует, что коммерческим банкам просто необходима разработка и внедрение в процесс инновационных проектов, связанных, в первую очередь с оценкой рисков, возникающих при оценке кредитоспособности клиента. Создание и развитие специализированных подразделений по выявлению наличия рисков заемщика, является одним из важнейших инструментов по минимизации потерь коммерческими банками при выдаче кредитных продуктов. Так как создание подобных подразделений с высококвалифицированными сотрудниками, поможет определить возможность возникновения потерь банка при кредитовании клиента, оценить возможность положительной кредитной истории с клиентом, а также в течении кредитования сформировать необходимый резерв в случае невозможности клиента платить по своим обязательствам перед банком.

Наибольших успехов в этом виде банковского бизнеса добьются те кредитные организации, которые раньше других создадут соответствующие внутренние механизмы, позволяющие эффективно работать на рынке банковских услуг. 


\section{Библиографический список}

1. Деньги. Кредит. Банки.: учеб. для вузов / Под ред. Жукова Е.Ф.- М.: Юнити-ДАНА, 2015. - 600 с.

2. Джикович В. / Банки не уйдут в отрыв // the Chief. - 2016. - № 3 (07). - C. 24-26.

3. Ершов Д. / Денежно-кредитные меры в условиях кризиса [Электронный ресурс] / Официальный сайт.- Pежим доступа: http://www.asros.ru/media/File/news/Erchov.pdf

4. Инвестиции в реальный сектор экономики / Изряднова О. // Российская экономика: тенденции и перспективы. - 2014. - № 9.- С. 32-35.

5. Иноземцева Ю.В. Теоретические аспекты и методика анализа финансовых результатов от операций с корпоративными клиентами коммерческого банка // Аудит и финансовый анализ. - 2014. - № 2. - С. 154-162.

6. Корпоративные клиенты уходят из мелких банков в более крупные [Электронный ресурс] / Официальный сайт. - Режим доступа: http://www.alti.ru/business/business-39.html (17.03.2017).

7. Кредитование бизнеса в условиях финансовой нестабильности / Шевчук Д. // Финансовая газета. - 2013. № 1.- С. 7-8.

8. Кредитование в условиях кризиса // Справочник экономиста - 2015. - № 4.- С. 99-103.

9. Кредитование малого бизнеса в условиях нестабильной финансовой ситуации / Чибисов А.А. [Электронный ресурс] / Официальный сайт.- Режим доступа: //http://www.finanal.ru/bankovskie-prodakty/problembankovskogo-kreditovaniya-malogo-bisnesa?page $=0.0$. (12.02.2017).

10. Кредитование экономики: тенденции и проблемы / Юлинкова И.Б. // Финансы и бизнес. - 2015. - № 3. - С. $59-66$.

11. Кроливецкая В.Э., Тихомирова Е.В. / Банки в системе инвестиционного финансирования реального сектора экономики России // Деньги и кредит. - 2013 г. - № 11.- С. 22-28.

12. Глазьев С.Ю. Великая цифровая революция: вызовы и перспективы для экономики XXI века. https://glazev. $\mathrm{ru} /$

13. РИА Новости, Наука,, СМИ. 2. Цифровая экономика: как специалисты понимают этот термин. https://ria. $\mathrm{ru} / \mathrm{science}$ 